\title{
Efficacy of Myofunctional Therapy Associated with Voice Therapy in the Rehabilitation of Neurogenic Oropharyngeal Dysphagia: a pilot study
}

\author{
Bruno Francisco de Fraga ${ }^{1}$ Sheila Tamanini de Almeida ${ }^{2}$ Márcia Grassi Santana ${ }^{3}$ Mauriceia Cassol ${ }^{2}$ \\ ${ }^{1}$ Rehabilitation Post-Graduation Program (PPGCR), Universidade \\ Federal de Ciências da Saúde de Porto Alegre (UFCSPA), Porto \\ Alegre, Rio Grande do Sul, Brazil \\ 2 Department of Speech Therapy, Universidade Federal de Ciências da \\ Saúde de Porto Alegre (UFCSPA), Porto Alegre, RS, Brazil

\begin{abstract}
Address for correspondence Bruno Francisco de Fraga, MSc, Programa de Pós-graduação em Ciências da Reabilitação, Universidade Federal de Ciências da Saúde de Porto Alegre, rua Serra da Mocidade, 112, Porto Alegre, RS, 91150440, Brazil (e-mail: bruno.defraga@live.com).
\end{abstract}

${ }^{3}$ Speech Therapy Service, Irmandade da Santa Casa de Misericórdia de Porto Alegre (ISCMPA), Porto Alegre, Brazil

Int Arch Otorhinolaryngol 2018;22:225-230.

\begin{abstract}
Keywords

- deglutition disorders

- voice training

- stroke

Introduction Dysphagia causes changes in the laryngeal and stomatognathic structures; however, the use of vocal exercises is poorly described.

Objective To verify whether the therapy consisting of myofunctional exercises associated with vocal exercises is more effective in rehabilitating deglutition in stroke patients.

Methods This is a pilot study made up of two distinct groups: a control group, which performed only myofunctional exercises, and an experimental group, which performed myofunctional and vocal exercises. The assessment used for oral intake was the functional oral intake scale (FOIS).

Results The FOIS levels reveal that the pre-therapy median of the experimental group was 4 , and increased to 7 after therapy, while in the control group the values were 5 and 6 respectively. Thus, the experimental group had a statistically significant difference between the pre- and post-therapy assessments $(p=0.039)$, which indicates that the combination of myofunctional and vocal exercises was more effective in improving the oral intake levels than the myofunctional exercises alone $(p=0.059)$. On the other hand, the control group also improved, albeit at a lower rate compared with the experimental group; hence, there was no statistically significant difference between the groups post-therapy ( $p=0.126)$.

Conclusion This pilot study showed indications that using vocal exercises in swallowing rehabilitation in stroke patients was able to yield a greater increase in the oral intake levels. Nevertheless, further controlled blind clinical trials with larger samples are required to confirm such evidence, as this study points to the feasibility of conducting this type of research.
\end{abstract}

received

February 3, 2016

accepted

July 11, 2017

published online

August 28, 2017
DOI https://doi.org/

10.1055/s-0037-1605597.

ISSN $1809-9777$.
Copyright $(2018$ by Thieme Revinter

Publicações Ltda, Rio de Janeiro, Brazil
License terms

(ㄷ) (i) $\ominus$ (5) 


\section{Introduction}

Deglutition ${ }^{1-4}$ is the process through which the food bolus passes from the oral cavity to the stomach, and it is basically divided into three phases: the oral phase, the pharyngeal phase, and the esophageal phase. When some change takes place in one deglutition phase or between phases, dysphagia occurs. Among the symptoms ${ }^{1,5-11}$ that arise are chocking, coughing, nasal reflux, asphyxia, malnourishment, dehydration, and aspiration pneumonia. This setting may also lead to prolonged hospitalization and even death.

Regarding the larynx structures involved in deglutition, three pairs of laryngeal folds stand out: the vocal folds, which, besides being responsible for producing sound during phonation, also act as a sphincter during deglutition; the aryepiglottic folds, which are responsible for guiding the food bolus laterally to pass through the piriform recesses and play a role in supraglottic closure; and the vestibular folds, whose role is to contribute to the glottic closure by contracting the thyroarytenoid muscle., 32

Thus, the larynx plays an important role in the pharyngeal phase of deglutition, since it helps carry the food bolus and protect the lower airway through the glottic closure and through its anterior-superior movement, which contributes to increase the pharyngeal space. These mechanisms aid the passage of the food bolus to prevent tracheal aspiration. ${ }^{1,2,4,8}$

Stroke is one of the cerebrovascular diseases that may affect the deglutition process. This condition can lead to neurogenic oropharyngeal dysphagia, since it causes anatomic and functional changes in the musculature and nervous system. Worldwide, stroke victims represent around $10 \%$ of the patients, two thirds of whom will survive the event. However, $50 \%$ will bear some permanent deficiencies that will impact their quality of life. ${ }^{5,10,13-15}$

In deglutition rehabilitation therapy, vocal exercises that contribute to the increase in mobility and pharyngeal and laryngeal musculature strength may be used. ${ }^{16}$ This therapeutic line aims to eliminate the risk of a choking event and the consequent tracheal aspiration that may lead to pneumonia.

The vocal techniques that may be employed are reverse phonation, ${ }^{17}$ vocal fry, ${ }^{18}$ blowing and high-pitched sound, ${ }^{19}$ semi-occluded vocal tract exercises such as vibrants, bilabial fricative, prolonged $\mathrm{B}$, hands-over-mouth exercise, and phonation in resonance tubes, ${ }^{20,21}$ inhalation phonation, musical scale, yawning/sighing, humming, thrust, ${ }^{22}$ and voiced postalveolar fricative. ${ }^{23}$

In this context, this research aimed to verify whether therapy with myofunctional exercises associated with vocal exercises is more effective than the therapy that uses exclusively myofunctional exercises to rehabilitate the neurogenic oropharyngeal dysphagia in persons after stroke. This proposal is based on the report of the literature ${ }^{15,24-26}$ regarding the need to conduct studies that could support the speechlanguage treatment approach.

\section{Methodology}

The present research is a pilot study that was approved by the committee of research ethics of the institution involved under protocol number 723,678/14.

In order to meet the research design requirements, the assessment and therapies were performed by different researchers. The researcher responsible for the pre- and posttherapy assessments was blinded to the type of therapy used and to the groups to which the subjects belonged. The subjects, in turn, were also blinded, since they were not aware of whether they had been assigned to the control or experimental group. After the first assessment, the subjects were then assigned to the research groups randomly according to a randomized number list generated on the website random.org.

The samples comprised 10 patients from one Stroke Unit from the city of Porto Alegre (in the state of Rio Grande do Sul, Brazil) who had received the neurologic diagnosis of ischemic stroke and the speech-therapy diagnosis of oropharyngeal dysphagia. This sample was characterized as a convenience sample, and was split into two groups with five subjects each. The intervention group underwent therapy with myofunctional exercises associated with vocal exercises, while the control group underwent therapy exclusively with myofunctional exercises.

The inclusion criteria were: being 18 years old or older, having been diagnosed with stroke, signing the term of free and informed consent, not having other associated neurological pathologies, not having undergone previous speechtherapy rehabilitation intervention, and performing the therapeutic exercises required. The exclusion criterion was having intercurrences during the treatment that could impact the research goals.

The assessment was made up of three parts: one voice assessment performed using the grade of change, roughness, breathiness, asthenia, strain and instability (GRBASI) scale, ${ }^{27,28}$ one assessment of the oral intake performed using the functional oral intake scale (FOIS), ${ }^{13}$ and one sensorymotor-orofacial assessment performed using the Marchesan, Berrentin-Felix, Genaro, Rehder (MBGR) protocol ${ }^{29}$ adapted by the researchers. Foods standardized in measures and consistencies by the Gugging swallowing screen (GUSS) ${ }^{30}$ were used to classify the oral intake levels through the FOIS.

After the assessment, the researcher filled out a file with the results indicating the musculature to be dealt with, and forwarded it to the researcher team responsible for administering the therapy. These assessments were repeated by the end of the therapy to compare the results and verify the evolution of the cases.

The techniques used were described in a therapeutic manual to be followed by the researchers involved in the therapy so as to guarantee procedural uniformity. This manual was divided per musculature area: mobility and strength of lips, tongue, cheeks, and soft palate, laryngeal mobility, and laryngeal glottal closure. The manual also listed the number of repetitions and the exercise load that were to be used for each indication in the results files. 
Table 1 Oral intake level progression

\begin{tabular}{|c|c|c|c|c|c|c|c|c|}
\hline & & & 1 & 2 & 5 & 6 & 7 & \\
\hline \multirow[t]{4}{*}{ EG } & \multirow[t]{3}{*}{ Initial FOIS } & 1 & & $1^{*}$ & & 0 & 0 & 1 \\
\hline & & 4 & & 0 & & $1^{*}$ & $1^{*}$ & 2 \\
\hline & & 5 & & 0 & & 0 & $2^{*}$ & 2 \\
\hline & \multicolumn{2}{|l|}{ Total } & & 1 & & 1 & 3 & 5 \\
\hline \multirow[t]{4}{*}{ CG } & \multirow[t]{3}{*}{ Initial FOIS } & 1 & $1^{* *}$ & & 0 & 0 & & 1 \\
\hline & & 3 & 0 & & $1^{*}$ & 0 & & 1 \\
\hline & & 5 & 0 & & 0 & $3^{*}$ & & 3 \\
\hline & \multicolumn{2}{|l|}{ Total } & 1 & & 1 & 3 & & 5 \\
\hline
\end{tabular}

Abbreviations: CG, control group; EG, experimental group; FOIS, functional oral intake scale. Notes: *number of patients who progressed; **number of patients who did not progress.

The subjects underwent therapy daily for a total of eight sessions: one initial assessment session and one therapy session on the same day, six therapy-only sessions per day after that, and one final assessment session. However, aiming to preserve the benefits of randomization and the balanced distribution of the prognostic factors, this sample was analyzed regarding the intention to treat, thus the subjects had to attend at least five sessions to be included in the research.

When the subject belonged to the control group, the laryngeal vocal exercises were not performed even if they were indicated in the results file. However, both the control and experimental groups performed the same myofunctional exercises. The prescription of the exercises that each subject should perform met their needs to maintain the clinical applicability of the study. This means that the subject did not do all exercises, but rather only the ones required in his or her case. Likewise, no more than two myofunctional exercises or more than one vocal exercise were performed for the same goal.

The myofunctional therapy was made up of the following exercises: lip protrusion and retrusion; protruded and retruded lip snapping; lip stretching; sustained lit protrusion; lip counter-resistance; occlude lip lateralization to the left and to the right; tongue protrusion and retrusion; tongue lateralization to the left and to the right; pushing the tongue in anterior and lateral counter-resistance; exaggerated raising and lowering of the dorsum of the tongue; tongue suction on the palate; tongue rotation in the oral vestibule; tongue snapping; cheek counter-resistance with the tongue; cheek contraction with resistance to the left and to the right; cheek inflating; cheek sucking; and blowing with no vocalization.

The vocal therapy was made up of the following exercises: plosive sound; effort/thrust; semi-occluded vocal tract with glottal firmness or vibrant sound; emission in maximum phonation time; and vocal fry. The techniques used for laryngeal raising and lowering were: musical scale for elevation alternated with voiced postalveolar fricative or tongue snapping associated with nasal sound along with yawningsighing for lowering.

The statistical tests used to analyze and compare the data were: the Wilcoxon test for pre- and post-therapy intragroup analysis, the Mann-Whitney test for pre- and post-therapy intergroup analysis, and the Student $t$-test for mean age analysis. The value of $p<0.050$ was adopted to verify statistical significance. The software used for the analyses was the Statistical Package for the Social Sciences (SPSS, IBM Corp., Armonk, NY, US), version 22.0.

\section{Results}

The results obtained for age show that the experimental group's mean age was $73.2 \pm 7.6$ years, while the control group's mean age was $63.8 \pm 12.9$ years, with no statistically significant difference $(p=0.200)$.The sex distribution was the same in both groups, with $40 \%$ of females and $60 \%$ of males in each group.

- Table 1 shows the data cross-checking regarding the progression of the oral diet through the FOIS. In the experimental group, all subjects improved, while one subject did not in the control group. In the control group, two subjects underwent six therapy sessions, while the others completed the whole therapeutic period proposed of seven therapy sessions. In the experimental group, one subject underwent five therapy sessions, one underwent six sessions, and the others completed the whole therapeutic period.

- Table 2 shows the medians of the pre- and post-therapy oral intake levels, as well as their respective $p$-values. The post-therapy improvement of the experimental group was statistically significant $(p=0.039)$. The value of $p=0.059$ for

Table 2 Median of the pre- and post-therapy oral intake levels

\begin{tabular}{|l|l|l|l|}
\hline & $\begin{array}{l}\text { EG } \\
\text { [min;max] }\end{array}$ & $\begin{array}{l}\text { CG } \\
{[\text { min;max] }}\end{array}$ & $\begin{array}{l}\text { Intergroup } \\
\text {-value }\end{array}$ \\
\hline Initial FOIS & $4[1 ; 5]$ & $5[1 ; 5]$ & 0.822 \\
\hline Final FOIS & $7[2 ; 7]$ & $6[1 ; 6]$ & 0.126 \\
\hline Intragroup p-value & $0.039^{*}$ & $0.059^{* *}$ & \\
\hline
\end{tabular}

Abbreviations: CG, control group; EG, experimental group; FOIS, functional oral intake scale.

Notes: "statistically significant; **tendency to be statistically significant. 
Table 3 Voice markers pre- and post-therapy

\begin{tabular}{|l|l|l|l|l|l|l|l|l|}
\hline & Intragroup & & $\mathrm{G}[\mathrm{min} ; \mathrm{max}]$ & $\mathrm{R}[\mathrm{min} ; \mathrm{max}]$ & $\mathrm{B}[\mathrm{min} ; \mathrm{max}]$ & $\mathrm{A}[\mathrm{min} ; \mathrm{max}]$ & $\mathrm{S}[\mathrm{min} ; \mathrm{max}]$ & $\mathrm{I}[\mathrm{min} ; \mathrm{max}]$ \\
\hline EG & & initial & $2[1 ; 3]$ & $1[1 ; 2]$ & $1[1 ; 3]$ & $1[0 ; 2]$ & $0[0 ; 1]$ & $1[1 ; 2]$ \\
\hline & & final & $1[1 ; 3]$ & $1[0 ; 1]$ & $0[0 ; 3]$ & $0[0 ; 2]$ & $0[0 ; 0]$ & $1[0 ; 1]$ \\
\hline & & $p$-value & 0.157 & 0.102 & $0.059^{*}$ & 0.102 & 0.317 & 0.157 \\
\hline CG & & initial & $1[1 ; 3]$ & $1[1 ; 2]$ & $1[0 ; 2]$ & $1[0 ; 3]$ & $0[0 ; 1]$ & $1[1 ; 2]$ \\
\hline & & final & $1[1 ; 2]$ & $1[0 ; 1]$ & $0[0 ; 1]$ & $0[0 ; 2]$ & $0[0 ; 1]$ & $1[0 ; 1]$ \\
\hline & & p-value & 0.157 & 0.317 & 0.180 & 0.180 & 1.000 & 0.157 \\
\hline & $\begin{array}{l}\text { Intergroup } \\
p \text {-value }\end{array}$ & initial & 0.650 & 0.513 & 0.178 & 0.914 & 1.000 & 1.000 \\
\hline & & final & 0.881 & 0.513 & 0.881 & 0.606 & 0.317 & 1.000 \\
\hline
\end{tabular}

Abbreviations: A, asthenia; B, breathiness; CG, control group; EG, experimental group; G, grade of change; I, instability; R, roughness; S, strain. Note: *Tendency to be statistically significant.

the control group indicated a tendency of being statistically significant.

- Table 3 shows the values of the medians regarding the voice quality markers through the GRBASI scale, as well as their respective $p$-values. Only the marker breathiness in the experimental group tended to be statistically significant, with $p=0.059$ between the pre- and post-therapy assessments.

\section{Discussion}

When the data regarding the oral intake levels between the groups (-Table 1) are analyzed, the median shows a more marked increase in the intake levels in the FOIS, from 4 to 7 in the experimental group, while the control group increased from 5 to 6 . This indicates that the association of myofunctional and vocal exercises more positively and effectively contributes to deglutition rehabilitation than only myofunctional exercises.

Another noteworthy fact is that both groups had a subject at level 1, but only the one in the experimental group evolved to level 2, which enabled a minimal oral offer, so that the direct deglutition therapy could be administered. It is important to highlight that, although the sample was evaluated regarding the intention to treat, both of these subjects completed the whole therapeutic period proposed.

Regarding the GRBASI scale, only the results of breathiness tended to be statistically significant between the preand post-therapy assessments in the experimental group (-Table 3). It must the pointed out that this is one of the voice markers related to glottal closure, since, when it is inefficient, air escapes and causes what is identified as breathiness. $^{31}$ This information may provide clues about the contribution of vocal exercises in the rehabilitation of swallowing.

Thus, it is clear that the experimental group significantly improved due to the inclusion of vocal exercises that complemented the therapy. It is known that the vocal techniques are effective in modifying glottal closure and laryngeal mobility, ${ }^{17-23}$ and that these mechanisms are involved in airway protection. ${ }^{1-4,8,12}$ However, these more detailed re- ports in the literature about vocal techniques still focus largely on the treatment of dysphonia.

The efficacy of vocal exercises can be explained by the fact that they allow a great increase in vibration and movement of the laryngeal and pharyngeal structures, mainly the vocal folds, which thus leads to the increase in the vibration amplitude of their mucosa. This increase in vibration favors mobility and the adduction process, which, in turn, improves glottal closure. ${ }^{16-23}$

It is known that better glottal closure derives from the improvement in the action of intrinsic laryngeal muscles directly linked to voice production, particularly the lateral cricoarytenoid adductors and the transverse and oblique arytenoid muscles. As for laryngeal mobility, its improvement derives from the better movement of the suprahyoid and infrahyoid muscles. The actions of the geniohyoid muscles, which are responsible for the elevation and forward thrust of the hyoid bone; of the cricopharyngeal and thyreopharyngeal muscles, which are able to raise all the larynx; and of the sternohyoid, sternothyroid, and omohyoid muscles, which lower the larynx, ${ }^{3,32}$ stand out.

Regarding the use of vocal exercises, one example is the Lee Silverman Voice Treatment (LSVT, Tucson, AZ, US) method used in Parkinson disease patients, which has been internationally recognized for its good results. This approach basically consists of using vocal exercises to work with the voice production, speech, and deglutition functions, and focuses on an intensive, short-term therapy. ${ }^{33,34}$

Besides this method, there are other examples of intensive voice therapy that, although have not been used to treat dysphagia, contribute to building knowledge on intensive therapy, and may aid in adopting vocal exercises that prove effective in improving glottal closure and laryngeal mobility. These methods are the Intensive Short-Term Vocal Therapy (IVT) ${ }^{35}$ and the Brazilian Intensive Voice Therapy (BIVT). ${ }^{36}$ These intensive therapeutic approaches last between a few days and a few weeks, and focus on several sessions a day.

With that in mind, future research must also use the concept of intensive therapy in dysphagia, since the results of the present research derived from a therapeutic plan focused on seven therapy sessions, which can be considered a form of 
intensive therapy given its length. In this line, the study by Inaoka and Albuquerque ${ }^{37}$ also proves that significant results can be obtained in improving deglutition with less than ten days of therapy.

There is currently more research that aims to establish the efficacy of speech therapy. ${ }^{11,22,38,39}$ Although there are many studies on the methods to verify deglutition conditions, ${ }^{15,37}$ researchers increasingly subscribe more to the idea that there should be an investment in controlled blind studies on the efficacy of speech therapy rehabilitation in dysphagia. ${ }^{15,24-26,40-43}$ The study by Oremus et al $^{15}$ contributes to the idea that new assessment instruments must be created only when there is a gap in knowledge, and that the ability to produce knowledge that justifies the work of the speech therapist is hindered by the excessive and discrepant instruments used. For instance, this hampers systematic revisions that could provide consensus for the therapeutic conduct.

In this sense, the main finding of the present research contributes to this discussion, as its goal was to assess the efficacy of speech therapy, that is, it aimed to verify whether the association between myofunctional exercises and vocal exercises was more effective in the rehabilitation of neurogenic oropharyngeal dysphagia. It was observed that the experimental group, which combined vocal and myofunctional exercises in therapy, obtained better results, with a statistically significant difference between the pre- and posttherapy assessments (-Table $\mathbf{2}$ ).

Although there was a statistically significant difference for the experimental group, no such difference was found between groups. This is because the control group also improved, although with lower efficacy than the experimental group. The statistically significant trend observed in the control group might be due to the small sample.

On the other hand, when the whole sample is analyzed (-Table 1), it can be seen that $90 \%$ of the subjects had an improvement in oral intake levels, and that none had aspiration pneumonia events. This matches the evidence that speech therapy for dysphagia yields positive results ${ }^{11,22,37-39}$ and, even if there is no improvement in the function, the speech therapists must act early by managing food consistency. Furthermore, they can aid in indicating an alternative feeding way to prevent aspiration pneumonia and the consequent worsening of the patients' clinical condition and the increasing hospital costs.

Regarding the rehabilitation of deglutition in the acute and subacute moments of stroke, it must also be taken into account that the spontaneous recovery process and neuroplasticity may entail doubts about the results of speech therapy rehabilitation. ${ }^{37}$ However, it can be seen that the alterations are reverted more quickly and with fewer intercurrences when early speech therapy rehabilitation is administered. ${ }^{11,37,39}$ Likewise, the present study showed that myofunctional exercises associated with vocal exercises yield better improvement of the oral intake levels.

The spontaneous recovery can be explained since the deglutition musculature has bilateral control in the motor cortex. Given the evidence that motor and sensory activities can produce adaptive changes in the brain circuitry that contribute to anatomically reorganizing the central nervous system, ${ }^{32}$ it is inferred that neuroplasticity acts in the neuronal reorganization in non-affected areas of the hemisphere. ${ }^{44}$

Therefore, this research indicated that the association between the two types of techniques has a more positive impact on deglutition rehabilitation. Nonetheless, studies with larger samples are important to confirm this finding. In addition, studies must also be performed to analyze the efficacy of each vocal technique in rehabilitating deglutition. There is even a need for a greater approach and use of the concepts of intensive therapy and neuroplasticity that point to a promising path to establish solid scientific evidence on the efficacy of the speech therapy intervention.

\section{Conclusion}

This pilot study enabled the observation of indications that the association of myofunctional and vocal exercises was more effective to rehabilitate deglutition than myofunctional exercises alone. Moreover, a greater increase in the progression of oral intake levels was observed in the experimental group. However, further controlled blind studies with larger samples are required to better confirm these findings, as this study points to the feasibility of conducting this type of research.

In this context, the authors also intend to contribute to highlight the importance and efficacy of speech therapy rehabilitation, pointing out that new practices of intensive therapy in dysphagia are promising and must be present in future researches.

\section{References}

1 Bakheit AMO. Management of neurogenic dysphagia. Postgrad Med J 2001;77(913):694-699

2 Logemann JA. Evaluation and Treatment of Swallowing Disorders. San Diego: College-Hill Press Inc; 1983

3 Matsuo K, Palmer JB. Anatomy and physiology of feeding and swallowing: normal and abnormal. Phys Med Rehabil Clin N Am 2008;19(04):691-707, vii

4 Yamada EK, Siqueira KO, Xerez D, Koch HA, Costa MMB. [The influence of oral and pharyngeal phases on the swallowing dynamic]. Arq Gastroenterol 2004;41(01):18-23

5 Altman KW, Schaefer SD, Yu GP, et al; Neurolaryngology Subcommittee of the American Academy of Otolaryngology-Head and Neck Surgery. The voice and laryngeal dysfunction in stroke: a report from the Neurolaryngology Subcommittee of the American Academy of Otolaryngology-Head and Neck Surgery. Otolaryngol Head Neck Surg 2007;136(06):873-881

6 Langdon C, Blacker D. Dysphagia in stroke: a new solution. Stroke Res Treat 2010;2010:1-6

7 Martino R, Foley N, Bhogal S, Diamant N, Speechley M, Teasell R. Dysphagia after stroke: incidence, diagnosis, and pulmonary complications. Stroke 2005;36(12):2756-2763

8 Palmer JB, Drennan JC, Baba M. Evaluation and treatment of swallowing impairments. Am Fam Physician 2000;61(08): 2453-2462

9 Ramsey DJC, Smithard DG, Kalra L. Early assessments of dysphagia and aspiration risk in acute stroke patients. Stroke 2003;34(05): $1252-1257$ 
10 Terré R, Mearin F. Oropharyngeal dysphagia after the acute phase of stroke: predictors of aspiration. Neurogastroenterol Motil 2006;18(03):200-205

11 White GN, O'Rourke F, Ong BS, Cordato DJ, Chan DKY. Dysphagia: causes, assessment, treatment, and management. Geriatrics 2008;63(05):15-20

12 Samlan RA, Webster KT. Swallowing and speech therapy after definitive treatment for laryngeal cancer. Otolaryngol Clin North Am 2002;35(05):1115-1133

13 Crary MA, Mann GDC, Groher ME. Initial psychometric assessment of a functional oral intake scale for dysphagia in stroke patients. Arch Phys Med Rehabil 2005;86(08):1516-1520

14 Cuenca RM, Malafaia DT, Souza GD, et al. Dysphagic syndrome. ABCD Arq Bra Cir Dig. 2007;20(02):116-118

15 Oremus M, Santaguida P, Walker K, Wishart LR, Siegel KL, Raina P. Studies of stroke rehabilitation therapies should report blinding and rationalize use of outcome measurement instruments. J Clin Epidemiol 2012;65(04):368-374

16 Behlau M, Ed. Voice: the specialist's book. 1st ed. vol. 2. Rio de Janeiro: Revinter; 2010

17 Finger LS, Cielo CS. Acoustic vocal modifications produced by reverse phonation. Rev Soc Bras Fonoaudiol 2009;14(01):15-21

18 Bolzan GP, Cielo CA, Brum DM. Effects of vocal fry incomplete glottal closure. Rev CEFAC. 2008;10(02):218-225

19 Maia MEO, Maia MO, Gama ACC, Behlau M. Immediate effects of the high-pitched blowing vocal exercise. J Soc Bras Fonoaudiol 2012;24(01):1-6

20 Fouquet ML, Vieira TPG, Murata CJM, Gonçalves AJ. Hands-overmouth exercise in supracricoid horizontal partial laryngectomy: initial study. Rev Soc Bras Fonoaudiol 2012;17(03):346-350

21 Sampaio M, Oliveira G, Behlau M. Investigation of the immediate effects of two semi-ocluded vocal tract exercises. Pro Fono 2008; 20(04):261-266

22 Mangilli LD, Amoroso MRM, Nishimoto IN, Barros APB, Carrara-de Angelis E. Voice, deglutition and quality of life of patients with unilateral vocal cords mobility alteration prior and post speech therapy. Rev Soc Bras Fonoaudiol 2008;13(02):103-112

23 D'Avila H, Cielo CA, Siqueira MA. Fricative hearing sound /ž/: vocal modifications. Rev CEFAC. 2010;12(06):915-924

24 Speyer R, Baijens L, Heijnen M, Zwijnenberg I. Effects of therapy in oropharyngeal dysphagia by speech and language therapists: a systematic review. Dysphagia 2010;25(01):40-65

25 Ferreira TS, Mangilli LD, Sassi FC, Fortunato-Tavares T, Limongi SCO, Andrade CRF. Speech and myofunctional exercise physiology: a critical review of the literature. J Soc Bras Fonoaudiol 2011; 23(03):288-296

26 Foley N, Teasell R, Salter K, Kruger E, Martino R. Dysphagia treatment post stroke: a systematic review of randomised controlled trials. Age Ageing 2008;37(03):258-264
27 Hirano M. Clinical examination of voice. New York: SpringerVerlag; 1981

28 Dejonckere PH, Remacle M, Fresnel-Elbaz E, Woisard V, Crevier L, Millet B. Reliability and clinical relevance of perceptual evaluation of pathological voices. Rev Laryngol Otol Rhinol (Bord) 1998; 119(04):247-248

29 Genaro KF, Berretin-Felix G, Rehder MIBC, Marchesan IQ. Orofacial myofunctional evaluation - MBGR Protocol. Rev CEFAC. 2009; 11(02):237-255

30 Trapl M, Enderle P, Nowotny M, et al. Dysphagia bedside screening for acute-stroke patients: the Gugging Swallowing Screen. Stroke 2007;38(11):2948-2952

31 Behlau M, Ed. Voice: the specialist's book. 1st ed. vol. 1. Rio de Janeiro: Revinter; 2010

32 Douglas CR, Ed. Applied Physiology for Speech Therapy. 2nd ed. Rio de Janeiro: Guanabara Koogan; 2007

33 El Sharkawi A, Ramig L, Logemann JA, et al. Swallowing and voice effects of Lee Silverman Voice Treatment (LSVT): a pilot study. J Neurol Neurosurg Psychiatry 2002;72(01):31-36

34 Sapir S, Ramig L, Fox C. Speech and swallowing disorders in Parkinson disease. Curr Opin Otolaryngol Head Neck Surg 2008;16(03):205-210

35 Patel RR, Bless DM, Thibeault SL. Boot camp: a novel intensive approach to voice therapy. J Voice 2011;25(05):562-569

36 Behlau M, Madazio G, Pacheco C, Gielow I. Intensive short-term voice therapy: the Brazilian experience. Perspec Voice Voice Disord. 2014;24:98-103

37 Inaoka C, Albuquerque C. Effectiveness of speech therapy in evolution of oral ingestion in patients with post stroke Oropharyngeal Dysphagia. Rev CEFAC. 2014;16(01):187-196

38 Silvério CC, Hernandez AM, Gonçalves MIR. Oral intake of hospitalized patient with neurogenic oropharyngeal dysphagia. Rev CEFAC. 2010;12(06):964-970

39 Furkim AM, Sacco ABF. Efficacy of speech therapy in neurogenic dysphagia using functional oral intake scale (FOIS) as a parameter. Rev CEFAC. 2008;10(04):503-512

40 Sallum RAA, Duarte AF, Cecconello I. Analytic review of dysphagia scales. Arq Bras Cir Dig 2012;25(04):279-282

41 Silva RG. [Efficacy of rehabilitation in oropharyngeal dysphagia]. Pro Fono 2007;19(01):123-130

42 Guimarães BTL, Furkim AM, Silva RG. Neuromuscular electrical stimulation in the rehabilitation of oropharyngeal dysphagia. Rev Soc Bras Fonoaudiol 2010;15(04):615-621

43 Pires EC, Sassi FC, Mangilli LD, Limongi SCO, Andrade CRF. Food in liquid consistency and deglutition: a critical review of the literature. Rev Soc Bras Fonoaudiol 2012;17(04):482-488

44 Bassi AER, Mitre EI, Silva MA OM, Arroyo MA S, Pereira MC. Association between dysphagia and topodiagnosis of the encephalic lesion post stroke. Rev CEFAC. 2004;6(02):135-142 